\title{
Role of modified biophysical profile in the management of post term pregnancy
}

\author{
Somya Singh ${ }^{1}$, Seema Rai ${ }^{2}$, Prajwal S. ${ }^{3}$, P. S. Rao ${ }^{3 *}$
}

\begin{abstract}
${ }^{1}$ Department of Obstetrics and Gynecology, Command Hospital, Lucknow, Uttar Pradesh, India ${ }^{2}$ Department of Obstetrics and Gynecology, Army Hospital RR, New Delhi, India

${ }^{3}$ Department of Obstetrics and Gynecology, Command Hospital AF, Bangalore, Karnataka, India
\end{abstract}

Received: 26 December 2017

Accepted: 06 January 2018

*Correspondence:

Dr. P. S. Rao,

E-mail: doctorpsrao@gmail.com

Copyright: (c) the author(s), publisher and licensee Medip Academy. This is an open-access article distributed under the terms of the Creative Commons Attribution Non-Commercial License, which permits unrestricted non-commercial use, distribution, and reproduction in any medium, provided the original work is properly cited.

\begin{abstract}
Background: Prolonged gestation complicates $5 \%$ to $10 \%$ of all pregnancies and confers increased risk to both the fetus and mother. In the west about $18 \%$ of all singleton pregnancies persist beyond 41 weeks, $10 \%$ (range, $3 \%$ to $14 \%$ ) continue beyond 42 weeks and $4 \%$ (range, $2 \%$ to $7 \%$ ) continue beyond 43 completed weeks in the absence of an obstetric intervention. The risks for prolonged and post-term pregnancy include obesity, nulliparity, maternal age $>30$ years. Apart from these racial and ethnic differences have also been cited to be the reasons for higher risk of prolonged and post-term pregnancy. Post term pregnancies are associated with various maternal and neonatal complications.

Methods: A prospective study was carried out at Department of Obstetrics and Gynaecology, Command Hospital, Central Command, Lucknow. 100 patients were selected and divided into two groups and were followed up till the delivery. Data so collected was subjected to analysis using Statistical Package for Social Sciences version 15.0.

Results: Majority of women enrolled in the study were aged above 25 years. Majority of women enrolled in the study were primigravida (67\%). The Mean BMI of women enrolled in the study was $24.2 \pm 3.43 \mathrm{~kg} / \mathrm{m} 2$ and the expectant and control groups were matched demographically and anthropometrically. The compromised modified biophysical profile was recorded in $33(66 \%)$ of women in expectant group. Rate of caesarean delivery was $30 \%$ in expectant and $46 \%$ in control group. In the expectant group, AFD was the most common indication for caesarean section while control group had NPOL as the most common indication for caesarean section. In the expectant group, mean AFI showed a declining trend with increasing gestational age.

Conclusions: It was concluded that expectant management using modified biophysical profile (MBPP) does not provide an additional value over prophylactically managed pregnancies. Although cesarean rate and NICU admission rates were lower in expectant group as compared to control group yet the utility of MBPP in expectant management could not be proven and needs further assessment in larger studies or pooled clinical trials.
\end{abstract}

Keywords: Amniotic fluid index, Modified biophysical profile, NST and post term pregnancy

\section{INTRODUCTION}

Prolonged gestation complicates $5 \%$ to $10 \%$ of all pregnancies and confers increased risk to both the fetus and mother. In the west about $18 \%$ of all singleton pregnancies persist beyond 41 weeks, $10 \%$ (range, $3 \%$ to $14 \%$ ) continue beyond 42 weeks and $4 \%$ (range, $2 \%$ to $7 \%$ ) continue beyond 43 completed weeks in the absence of an obstetric intervention. ${ }^{1}$ Apart from these racial and ethnic differences have also been cited to be the reasons 
for higher risk of prolonged and post-term pregnancy. ${ }^{2}$ Globally, nearly 5 to 10 percent of all pregnancies continue to at least 42 weeks gestation. ${ }^{3}$ In the absence of a national data base in India, the prevalence of pregnancies continuing 42 weeks or more has been reported to be ranging from $2 \%$ to $7.7 \%{ }^{4}$ 'Post-mature pregnancy' or 'post-maturity syndrome', which specifically describe the effects of intrauterine growth deficiency secondary to placental insufficiency in the prolonged gestation yet it is apparent that fewer than onethird of all post-term pregnancies will develop the true post-maturity syndrome, but the accurate diagnosis of the latter is all important, for almost one-quarter of all infants who develop the true post-maturity syndrome will die and hence its early and appropriate management is essential to ensure the maternal as well as perinatal physical and psychological wellbeing in view of the fact that continued intra-uterine existence beyond forty-two weeks gestation is associated with a high incidence of placental insufficiency, fetal post-maturity (dysmaturity), and increased risk of perinatal death. ${ }^{5}$

Common methods for fetal surveillance include fetal movement counting, non-stress test (NST), biophysical profile, modified biophysical profile (NST and amniotic fluid volume estimation) and contraction stress test. The fetal biophysical profile is one of the most widely accepted tests for the evaluation of fetal wellbeing in high risk cases. The original biophysical profile was described by Manning and includes study of five variables i.e. breathing movement, fetal tone, fetal body movement, amniotic fluid index and non-stress test. ${ }^{6}$ It needs two phase testing by ultrasound and external Doppler monitor to record fetal heart rate. The complete biophysical scoring is cumbersome, time consuming and expensive.

Nageotte et al presented a simplified version of assessment of fetal biophysical profile based on NST and AFI findings and termed it as modified biophysical profile (MBPP). ${ }^{7}$ MBPP suggested by Nageotte et al. combines Non-stress test (NST) as a short term marker of fetal status and the amniotic fluid index (AFI) as a marker of long term placental function and is easier to perform and less time consuming than complete biophysical profile, moreover it is considered to be as effective as complete biophysical profile. Despite its usefulness in assessment of perinatal risk and as a tool of fetal surveillance, there are limited studies on evaluation of Modified Biophysical Profile in management of postdated pregnancies. The present study was proposed to fill these gaps.

\section{METHODS}

$\mathrm{T}$ This was a prospective analytical case control study carried out in Department of OBG, Command Hospital, Lucknow from May 2013 to April 2014. Pregnant women of the study population who had completed 40 weeks of pregnancy were included. Pregnant women with obstetrical, surgical or medical complications contraindicated for vaginal delivery were excluded from the study. 100 patients were selected and 50 patients were assigned into two groups .Cases $(n=50)$, pregnant women fulfilling the inclusion criteria and not falling into the domain of exclusion criteria in whom fetal surveillance was carried out using Modified Biophysical Profile criteria and Controls $(n=50)$, pregnant women fulfilling the inclusion criteria and not falling into the domain of exclusion criteria in whom induction of labour was done prophylactically after completion of maximum of 40 weeks of pregnancy.

Women in control group were induced for labour immediately after completion of 40th week of pregnancy while those in case group were subjected to the following protocol- NST and AFI assessment twice a week or more frequently in case of decreased DFMC till 42 weeks of gestational age. Induction was done in case of-Nonreactive NST, oligohydramnios and those not delivering spontaneously at completion of 42 weeks of pregnancy and emergency LSCS was done if there was ominous NST. Progress of labour was monitored for all the cases irrespective of spontaneous / induction or LSCS decisions. All the women were followed up till the outcome of pregnancy.

Modified Biophysical Profile Criteria was used (Nonreactive NST, and/or AFI $<10 \mathrm{~cm}$ ). Following outcome were measured -incidence of spontaneous onset of labour between 40-42 weeks, induction for abnormal fetomaternal surveillance between 40-42 weeks and emergency LSCS for ominous NST. Change in AFI in cases between 40-42 weeks. Time of delivery in cases between 40-42 weeks. Data so collected was subjected to analysis using Statistical Package for Social Sciences version 15.0

\section{RESULTS}

The present study was carried out with an aim to evaluate the management of low risk post-dated pregnancy by modified biophysical profile in a tertiary care centre of India. For this purpose a total of 100 pregnant women fulfilling the inclusion criteria were enrolled in the study and were allocated to one of the two groups as given in Table 1.

Table 1: Group wise distribution of patients.

\begin{tabular}{|lllc|}
\hline Group & $\begin{array}{l}\text { Description } \\
\text { I }\end{array}$ & $\begin{array}{l}\text { No. of } \\
\text { patients }\end{array}$ \\
\hline & $\begin{array}{l}\text { Cases-managed using } \\
\text { modified biophysical } \\
\text { profile }\end{array}$ & 50 & 50 \\
\hline II & $\begin{array}{l}\text { Controls-Women in whom } \\
\text { prophylactic induction was } \\
\text { done at the end of } 40^{\text {th }} \text { week }\end{array}$ & 50 & 50 \\
\hline & & \\
\hline
\end{tabular}

According to Table 1, Group I comprised the case group in which of 50 post-dated pregnant women who were 
managed using modified biophysical profile and in whom pregnancy was continued till 42nd week of pregnancy and Group II comprised the control group in which of 50 post-dated pregnant women in whom induction of labour was done prophylactically after completion of maximum of 40 weeks of pregnancy.

Table 2: Age wise comparison of patients.

\begin{tabular}{|l|llllll|}
\hline $\begin{array}{l}\text { Age } \\
\text { group } \\
\text { (years) }\end{array}$ & Notal & \multicolumn{2}{l}{$\begin{array}{l}\text { Group I } \\
(\mathrm{n}=50)\end{array}$} & $\begin{array}{l}\text { Group II } \\
(\mathrm{n}=50)\end{array}$ \\
\hline$<20$ & 6 & 6.0 & 0 & 0.0 & 6 & 12.0 \\
\hline $21-25$ & 40 & 40.0 & 21 & 42.0 & 19 & 38.0 \\
\hline $26-30$ & 50 & 50.0 & 27 & 54.0 & 23 & 46.0 \\
\hline$>30$ & 4 & 4.0 & 2 & 4.0 & 2 & 4.0 \\
\hline $\begin{array}{l}\text { Mean } \\
\text { Age } \pm \text { SD } \\
\text { (Range) }\end{array}$ & $25.70 \pm 3.10$ & $26.00 \pm 2.70$ & $25.40 \pm 3.45$ \\
\hline
\end{tabular}

According to Table 2. Age of patients ranged from 18 to 32 years with a mean age of 25.70 and a standard deviation of 3.10 years. Maximum number of patients were aged $26-30$ years $(n=50 ; 50 \%)$.

Table 3: Comparison of patients according to gravidity.

\begin{tabular}{|lllllll|} 
Gravidity & \multicolumn{2}{c}{ Total } & \multicolumn{2}{c|}{ Group I } & \multicolumn{2}{c|}{$\begin{array}{c}\text { Group II } \\
(\mathbf{n = 5 0})\end{array}$} \\
& No. & $\%$ & No. & $\%$ & No. & \% \\
\hline G1 & 67 & 67.0 & 35 & 70.0 & 32 & 64.0 \\
\hline G2 & 28 & 28.0 & 13 & 26.0 & 15 & 30.0 \\
\hline G3 & 5 & 5.0 & 2 & 4.0 & 3 & 6.0 \\
\hline
\end{tabular}

According to Table 3, Majority of patients irrespective of their group were gravida 1. Minimum number of patients were gravida 3. Statistically, there was no significant difference between two groups with respect to gravida status $(\mathrm{p}=0.788)$.

Table 4: Comparison of patients according to BMI status.

\begin{tabular}{|lllllll|}
$\begin{array}{l}\text { BMI } \\
\text { status } \\
\left(\mathrm{kg} / \mathrm{m}^{2}\right)\end{array}$ & Notal & \multicolumn{3}{l}{$\begin{array}{l}\text { Group I } \\
(\mathrm{n}=50)\end{array}$} & \multicolumn{2}{l|}{$\begin{array}{l}\text { Group II } \\
(\mathrm{n}=50)\end{array}$} \\
\hline$\leq 18.5$ & 2 & 2.0 & 1 & 2.0 & 1 & 2.0 \\
\hline $18.5-25.0$ & 52 & 52.0 & 25 & 50.0 & 27 & 54.0 \\
\hline $25.0-30.0$ & 39 & 39.0 & 21 & 42.0 & 18 & 36.0 \\
\hline$\geq 30$ & 7 & 7.0 & 3 & 6.0 & 4 & 8.0 \\
\hline $\begin{array}{l}\text { Mean } \\
\text { BMI } \pm \text { SD } \\
\left(\mathrm{kg} / \mathrm{m}^{2}\right)\end{array}$ & $24.2 \pm 3.43$ & $24.3 \pm 3.45$ & $24.1 \pm 3.45$ \\
\hline
\end{tabular}

According to Table 4, BMI of patients ranged from 18 to $34 \mathrm{~kg} / \mathrm{m}^{2}$. Majority of patients $(\mathrm{n}=52 ; 52 \%)$ had BMI in the range of $18.5-25.0 \mathrm{~kg} / \mathrm{m}^{2}$. Mean BMI of patients was $24.2 \pm 3.43 \mathrm{~kg} / \mathrm{m}^{2}$.
Table 5: Outcome of electronic fetal monitoring in patients of group I.

\begin{tabular}{|lll|}
\hline Outcome & No. of patients & Percentage \\
\hline Fetal movements & & \\
\hline Normal & 41 & 82.0 \\
\hline Reduced & 9 & 18.0 \\
\hline Non-Reactive NST & 5 & 10 \\
\hline AFI <10 & 28 & 56.0 \\
\hline Compromised MBPP & 33 & 66.0 \\
\hline Induction done & 33 & 66.0 \\
\hline
\end{tabular}

According to Table 5, Fetal movements were reduced in $9(18 \%)$ cases. A total of $6(12 \%)$ cases had non-reactive NST. AFI $<10$ was recorded in $28(56 \%)$ cases. Induction was done in $33(66 \%)$ cases.

Table 6: Comparison of patients according to mode of delivery.

\begin{tabular}{|c|c|c|c|c|c|c|}
\hline \multirow{2}{*}{$\begin{array}{l}\text { Mode of } \\
\text { delivery }\end{array}$} & \multicolumn{2}{|c|}{ Total } & \multicolumn{2}{|c|}{$\begin{array}{l}\text { Group I } \\
(\mathbf{n}=50)\end{array}$} & \multicolumn{2}{|c|}{$\begin{array}{l}\text { Group II } \\
(\mathrm{n}=50)\end{array}$} \\
\hline & No. & $\%$ & No. & $\%$ & No. & $\%$ \\
\hline & 62 & 62 & & 70. & 27 & 54.0 \\
\hline LS & 38 & 38.0 & 15 & 30.0 & 23 & 46.0 \\
\hline
\end{tabular}

According to Table 6, total of $62(62 \%)$ cases had full term normal delivery. Though proportion of LSCS deliveries was higher in Group II (46\%) as compared to Group I $(30 \%)$ yet the difference was not significant statistically $(\mathrm{p}=0.099)$.

Table 7: Comparison of patients according to mode of delivery.

\begin{tabular}{|c|c|c|c|c|c|c|}
\hline \multirow[t]{2}{*}{ Indication } & \multicolumn{2}{|c|}{ Total } & \multicolumn{2}{|c|}{$\begin{array}{l}\text { Group I } \\
(n=50)\end{array}$} & \multicolumn{2}{|c|}{$\begin{array}{l}\text { Group II } \\
(\mathrm{n}=50)\end{array}$} \\
\hline & No. & $\%$ & No. & $\%$ & No. & $\%$ \\
\hline NA & 62 & 62.0 & 35 & 70.0 & 27 & 54.0 \\
\hline AFD & 17 & 17.0 & 10 & 20.0 & 7 & 14.0 \\
\hline DTA & 3 & 3.0 & 0 & 0 & 3 & 6.0 \\
\hline MSL & 6 & 6.0 & 3 & 6.0 & 3 & 6.0 \\
\hline NPOL & 12 & 12.0 & 2 & 4.0 & 10 & 20.0 \\
\hline
\end{tabular}

According to Table 7, in Group II, 27 (54\%) patients did not require LSCS whereas in Group I, 35 (70\%) did not require LSCS.

In Group II, acute fetal distress ( $\mathrm{n}=7 ; 14 \%)$, non-progress of labour $(n=3 ; 6 \%)$, meconium stained liquor $(n=3 ; 6 \%)$ and DTA $(\mathrm{n}=10 ; 20 \%)$ were the indications for LSCS whereas in Group I, acute fetal distress $(n=10 ; 20 \%)$, meconium stained liquor $(\mathrm{n}=3 ; 6 \%)$ and non-progress of labour $(n=2 ; 4 \%)$ were the indications for LSCS. Statistically, there was a significant difference between two groups with respect to indication for LSCS $(\mathrm{p}=0.042)$. 
Table 8: Comparison of patients according to birth weight of baby.

\begin{tabular}{|c|c|c|c|c|c|c|}
\hline \multirow{2}{*}{$\begin{array}{l}\text { Birth } \\
\text { weight of } \\
\text { baby }\end{array}$} & \multicolumn{2}{|c|}{ Total } & \multicolumn{2}{|c|}{$\begin{array}{l}\text { Group I } \\
(n=50)\end{array}$} & \multicolumn{2}{|c|}{$\begin{array}{l}\text { Group II } \\
(n=50)\end{array}$} \\
\hline & No. & $\%$ & No. & $\%$ & No. & $\%$ \\
\hline$<2.5 \mathrm{~kg}$ & 8 & 8.0 & 3 & 6.0 & 5 & 10.0 \\
\hline $2.5-3.5 \mathrm{~kg}$ & 90 & 90.0 & 45 & 90.0 & 45 & 90.0 \\
\hline$>3.5 \mathrm{~kg}$ & 2 & 2.0 & 2 & 4.0 & 0 & 0.0 \\
\hline
\end{tabular}

According to Table 8, majority of subjects irrespective of group had babies with birth weight 2.5 to $3.5 \mathrm{~kg}$. In Group II, there were $5(10 \%)$ babies with birth weight $<2.5 \mathrm{~kg}$ and none with birth weight $>3.5 \mathrm{~kg}$ whereas in Group I, there were $3(6 \%)$ babies with birth weight $<2.5$ $\mathrm{kg}$ and $2(4 \%)$ with birth weight $>3.5 \mathrm{~kg}$. Statistically, there was no significant difference between two groups with respect to birth weight $(\mathrm{p}=0.287)$.

Table 9: Comparison of patients according to Apgar score at 1 and $5 \mathrm{~min}$.

\begin{tabular}{|llllllllll|}
$\begin{array}{l}\text { Apgar } \\
\text { Score }\end{array}$ & Total & \multicolumn{2}{l}{$\begin{array}{l}\text { Group I } \\
(\mathbf{n}=50)\end{array}$} & \multicolumn{2}{l}{$\begin{array}{l}\text { Group II } \\
(\mathbf{n}=50)\end{array}$} & $\begin{array}{l}\text { Statistical } \\
\text { significance }\end{array}$ \\
\hline $\begin{array}{l}<\text { at } \\
1 \text { min }\end{array}$ & 14 & 14 & 7 & 14 & 7 & 14 & 0 & 1 \\
\hline $\begin{array}{l}<\text { at } \\
5 \text { min }\end{array}$ & 1 & 1 & 1 & 2 & 0 & 0 & 1.01 & 0.315 \\
\hline
\end{tabular}

According to Table 9, At 1 and 5 min after birth, there were $14(14 \%)$ and $1(1 \%)$ patients respectively with low Apgar (APGAR<7). At $1 \mathrm{~min}$, both the groups had equal number of babies with Apgar $<7(n=7 ; 14 \%)$.

At 5 min, the single case with Apgar $<7$ was in Group I. Statistically, there was no significant difference between two groups with respect to Apgar score at 1 and $5 \mathrm{~min}$ intervals $(\mathrm{p}>0.05)$.

Table 10: Comparison of patients according to need for NICU/NNU admission.

\begin{tabular}{|c|c|c|c|c|c|c|}
\hline \multirow{2}{*}{$\begin{array}{l}\text { NICU/NNU } \\
\text { admission }\end{array}$} & \multicolumn{2}{|c|}{ Total } & \multicolumn{2}{|c|}{$\begin{array}{l}\text { Group I } \\
(n=50)\end{array}$} & \multicolumn{2}{|c|}{$\begin{array}{l}\text { Group II } \\
(n=50)\end{array}$} \\
\hline & No. & $\%$ & No. & $\%$ & No. & $\%$ \\
\hline No & 67 & 67 & 30 & 69.0 & 37 & 74.0 \\
\hline Yes & 33 & 66 & 20 & 40.0 & 13 & 26.0 \\
\hline
\end{tabular}

According to Table 10, a total of 33 (33\%) babies required NICU/NNU admission. In Group I 20 (40\%) babies required NICU/NNU admission as compared to 13 $(26 \%)$ in Group II. But difference between groups was not significant statistically $(\mathrm{p}=0.137)$.

According to Table 11, with increasing gestational age a declining trend of AFI was observed. The association between AFI and gestational age was significant statistically too $(\mathrm{p}=0.001)$.
Table 11: Relationship between AFI and gestational age.

\begin{tabular}{|llll|}
\hline Gestational age & $\mathrm{n}$ & Mean AFI & SD \\
\hline Wk 40 & 1 & 8 & \\
\hline Wk 40+ & 36 & 9.69 & 1.43 \\
\hline Wk 41+ & 4 & 7.92 & 1.00 \\
\hline Wk 42 & 1 & 7.00 & \\
\hline
\end{tabular}

\section{DISCUSSION}

Management of pregnancies beyond term is a challenge. Technically, a pregnancy is considered to be post-term once it complete 42 weeks (294 days) of gestation. No doubt irrespective of the technical definition, continuation of a pregnancy beyond the term of 37 weeks is an issue both for the pregnant woman as well as for the obstetrician. It is thus essential that all the pregnancies going beyond the term should be kept under surveillance and an intervention should be made whenever indicated.

However, the issue as to what indications should be considered substantial enough to make an intervention remains unresolved and controversy still exists on the judicious approach to take such decision. Options for fetal surveillance include fetal movement counting, nonstress test, biophysical profile or modified biophysical profile (non-stress test plus amniotic fluid volume estimation), and contraction stress test. Over the years, biophysical profile assessment has shown a deterministic role in objective assessment of pregnancy beyond the usual term of 37 weeks. Biophysical profile assessment is comprehensive criteria for evaluation of fetal wellbeing as well as the environment surrounding it. ${ }^{8}$ However, recent evidence has suggested that modified biophysical profile assessment which utilizes only two criteria i.e. amniotic fluid index and stress test can also work as efficiently if not better as the comprehensive complete biophysical assessment (Nageotte et al). In present study, we made an attempt to evaluate the usefulness of Modified Biophysical Profile (MBPP) in management of low risk post-dated pregnancy in a tertiary health care centre of India.

Majority of pregnant women in both the groups were aged above 25 years. Although advancing maternal age is an identified risk factor for prolonged labour (Rao et al) ${ }^{9}$ yet in present study none of the pregnant women in either of two groups were advancing age group of $>35$ years as per the generally accepted criteria (Huisman et al)..$^{9,10}$

In present study majority of the pregnant women were gravida 1, had a BMI in the range of 18.5-25.0, though substantial number of women $(46 \%)$ were also in overweight and obese groups. Maternal age, parity and BMI have been shown to be strong predictors of prolonged pregnancy (Rao et al).

In Expectant group fetal monitoring revealed normal NST findings in 44 out of 50 subjects enrolled, however, 
AFI findings below the cut-off were observed in 28 $(56 \%)$ of the subjects. Collectively, $33(66 \%)$ of the pregnancies were found to have a compromised MBPP up to $42^{\text {nd }}$ week of pregnancy and hence they were subjected to induction. In a study by Alfirevic and Walkinshaw, the rate of MBPP abnormalities among pregnancies beyond 42 weeks of gestation was only $47.2 \% .{ }^{11}$ The difference in proportion of compromised MBPP between two studies could be attributed to use of different criteria for AFI. In present study, we followed the criteria of AFI abnormality to be $<10 \mathrm{~cm}$. However, Alfirevic and Walkinshaw used the criteria of AFI $<5 \mathrm{~cm}$ for the purpose of establishing MBPP abnormalities. ${ }^{11}$

33 of 50 women in Expectant group delivered before 42 weeks while remaining 17 were induced for delivery at the end of 42 weeks as per the requirements of protocol followed in the present study. Eventually, we found that cesarean rate was higher in Expectant group as compared to control group, however, the difference between two groups was not significant statistically $(\mathrm{p}=0.099)$. Thus, in this study active induction in control group led to an increased rate of cesarean section, though not at statistically significant extent. This is contrary to the findings of Cucco et al who observed that active induction did not increase the cesarean section rate. ${ }^{12}$ Paradoxical to this finding, Solis $\mathrm{J}$ et al found a higher cesarean rate $(71 \%)$ in post-term pregnancies managed by BPP scoring. ${ }^{13}$ Association of BPP/MBPP profile with cesarean rate is different in different studies. In another study by Nageotte et al, using MBPP the rate of cesarean section was $18 \%$ in expectant and 18 to $23 \%$ in two different control groups. The difference in cesarean section rate itself is highly dependent on the institutional policies. However, we are not in a position to comment over this issue as none of the authors previously have used this criteria for assessment and this criteria needs further standardization before it can be used in practice. Moreover, between groups difference in gestational age was also nominal ( 2 weeks at the most).

With respect to indications for cesarean section, fetal distress was the indication for cesarean section in $10 / 15$ $(66.7 \%)$ cesarean deliveries in expectant group whereas in control group it was non-progress of labour in 10/23 $(43.5 \%)$ cases. These observations are in accordance with the observations made by Tongsong et al who reported that rapid BPP is a reliable predictor of intrapartum fetal distress. ${ }^{14}$ The high prevalence of cases with fetal distress in present study could be attributed to the fact that the induction decision based on MBPP was indicator of fetal distress itself and the cases which were managed prophylactically did not have an indication of fetal distress when managed prophylactically.

With respect gender, birth weight, Apgar scores and NICU admission of babies too, the difference between two groups was not significant statistically. This is in accordance with the findings of Cochrane review by Lalor et al. (2008) who also found that biophysical profile assessment has no effect on poor outcome including number of babies that died, or number of babies who had low Apgar scores. ${ }^{15}$

In present study mean AFI values showed a gradual decrease with increasing gestational age. This finding is in accordance with the observations of Kofinas et al who reported a decreasing trend in AFI measurements with increasing gestational age of babies. ${ }^{16}$

In effect, the present study showed that there is no significant difference in outcome and complication rate in expectant pregnancy management using modified biophysical profile as compared to those managed prophylactically. The literature on this issue is scarce and limited, hence despite these insignificant differences in smaller studies, larger studies have the potential and capability to turn the perspective. Moreover, considering the post-term pregnancy to be high-risk, one has to depend on more sensitive criteria rather than more specific criteria, which is a limitation in evaluating the outcome.

The findings of present study are in agreement that MBPP does not add much value in expectant management and in our environment, induction at $40+$ weeks of gestation do not pose additional risk of poor outcome. Larger studies on the issue might reveal some additional facets of study. The present study, thus should be considered as a small effort and should be substantiated with larger trials.

\section{CONCLUSION}

On the basis of results obtained in present study and their analysis in the light of existing pool of knowledge, it was concluded that expectant management using modified biophysical profile does not provide an additional value over prophylactically managed pregnancies. Although cesarean rate and NICU admission rates were lower in expectant group as compared to control group yet the utility of MBPP in expectant management could not be proven and needs further assessment in larger studies or pooled clinical trials.

Funding: No funding sources

Conflict of interest: None declared

Ethical approval: The study was approved by the Institutional Ethics Committee

\section{REFERENCES}

1. Norwitz ER, Snegovskikh VV, Caughey AB. Prolonged pregnancy: when should we intervene? Clin Obstet Gynecol. 2007;50(2):547-57.

2. Caughey AB, Stotland NE, Washington AE, Escobar GJ. Who is at risk for prolonged and post-term pregnancy? Am J Obstet Gynecol. 2009 Jun;200(6):683.e1-5. 
3. Olesen AW, Westergaard JG, Olesen J. Perinatal and maternal complications related to postterm delivery: a national register-based study, 1978-1993. Am J Obstet Gynecol. 2003;189: 222-7.

4. Mukhopadhyay P, Chaudhuri RN, Paul B. Hospitalbased perinatal outcomes and complications in teenage pregnancy in India. J Health Popul Nutr. 2010 Oct;28(5):494-500.

5. Ingemarsson I, Kallen K. Stillbirths and rate of neonatal deaths in 76,761 postterm pregnancies in Sweden, 1982-1991: A register study. Acta Obstet Gynecol Scand. 1997;76:658-662.

6. Manning FA, Platt LD, Sipos L. Antepartum fetal evaluation: development of a fetal biophysical profile score. Am J Obstet Gynecol. 1980;136:787.

7. Nageotte MP, Towers CV, Asrat T, Freeman RK. Perinatal outcome with the modified biophysical profile. Am J Obstet Gynecol. 1994;170(6):1672-6.

8. Shah DM, Brown JE, Salyer SL, Fleischer AC, Boehm FH. A modified scheme for biophysical profile scoring. Am J Obstet Gynecol. 1989 Mar;160(3):586-91.

9. Rao A, Celik E, Poggi S, Poon L, Nicolaides KH. Fetal Medicine Foundation Prolonged Pregnancy Group. Cervical length and maternal factors in expectantly managed prolonged pregnancy: prediction of onset of labor and mode of delivery. Ultrasound Obstet Gynecol. 2008 Oct;32(5):646-51.

10. Huisman CM, Zwart JJ, Roos-Hesselink JW, Duvekot JJ, van Roosmalen J. Incidence and predictors of maternal cardiovascular mortality and severe morbidity in The Netherlands: a prospective cohort study. PLoS One. 2013;8(2):e56494.
11. Alfirevic Z, Walkinshaw SA. A randomised controlled trial of simple compared with complex antenatal fetal monitoring after 42 weeks of gestation. $\mathrm{Br}$ J Obstet Gynecol. 1995 Aug;102(8):638-43.

12. Cucco C, Osborne MA, Cibils LA. Maternal-fetal outcomes in prolonged pregnancy. Am J Obstet Gynecol. 1989 Oct;161(4):916-20.

13. Jiménez Solis G, Izquierdo Puente JC, Barraza Espinoza RM, Sánchez Tenorio E, García Alonso A. Biophysical profile in prolonged pregnancy. Another alternative of fetal surveillance. Ginecol Obstet Mex. 1990;58:284-8.

14. Tongsong T, Piyamongkol W, Anantachote A, Pulphutapong K. The rapid biophysical profile for assessment of fetal well-being. J Obstet Gynaecol Res. 1999 Dec;25(6):431-6.

15. Lalor JG, Fawole B, Alfirevic Z, Devane D. Biophysical profile for fetal assessment in high risk pregnancies (Review). Cochrane Database Syst Rev. 2008 Jan 23;(1):CD000038.

16. Kofinas A, Kofinas G. Differences in amniotic fluid patterns and fetal biometric parameters in third trimester pregnancies with and without diabetes. J Matern Fetal Neonatal Med. 2006 Oct;19(10):633-8.

Cite this article as: Singh $S$, Rai S, Prajwal S, Rao PS. Role of modified biophysical profile in the management of post term pregnancy. Int $\mathrm{J}$ Reprod Contracept Obstet Gynecol 2018;7:456-61. 